\title{
Varied Onset of Heart Ventricular Depolarization in Different Age Groups of Healthy Volunteers
}

\author{
K. KOZLÍKOVÁ ${ }^{1}$, M. TRNKA ${ }^{1}$ \\ ${ }^{1}$ Institute of Medical Physics, Biophysics, Informatics and Telemedicine, Faculty of Medicine, \\ Comenius University in Bratislava, Bratislava, Slovak Republic
}

Received July 9, 2019

Accepted October 15, 2019

\begin{abstract}
Summary
Group mean isopotential maps of initial parts of ventricular depolarization (QRS complex) in 4 age groups $(10,14,19$ and 22 years) of young healthy subjects, females and males, were analyzed using different increments between isopotential lines. It was found that the increment $0.1 \mathrm{mV}$ masks some features of the maps, which are seen only by smaller increment $(0.02 \mathrm{mV})$ : the time of appearance of maximum and minimum on the anterior chest, smaller voltage values of the extrema as usually published, minimum dominating over maximum in the youngest groups. Therefore, the often applied criterion for the QRS onset the increasing maximum on the anterior chest - should be reconsidered at least when it concerns the isopotential maps of children.
\end{abstract}

\section{Key words}

Body surface potential mapping • Ventricular depolarization • Child • Adult

\section{Corresponding author}

K. Kozlíková, Institute of Medical Physics, Biophysics, Informatics and Telemedicine, Faculty of Medicine, Comenius University in Bratislava, Sasinkova 2, 81372 Bratislava 1, Slovak Republic. E-mail: katarina.kozlikova@fmed.uniba.sk

\section{Introduction}

The twelve-lead electrocardiogram is an inexpensive, essential, reproducible, patient's friendly and non-invasive method how to detect electric abnormalities of the heart. However, because of limited area examined by the six chest leads and only the frontal plane examined by the limb leads, it does not give the full available information. This can be achieved by multi-lead recordings - body surface potential mapping - when a large number of electrodes is distributed over the whole chest including back. Although the recording of unipolar electrocardiograms is analogous to the standard twelvelead electrocardiography (except for the number of used electrodes), the display and evaluation differs. Instead of processing individual curves, images resembling geographical maps are displayed and analyzed.

The most detailed information available in noninvasive way offers a sequence of isopotential maps representing instantaneous distribution of electric voltage over the chest and its change over the time. Very frequently used form of their display are two-dimensional coloured or black-and-white images with isopotential lines that allow simple identification mainly of map minima and maxima and/or other typical map patterns useful for diagnostic purposes (Kozlíková 1990). These map patterns (features) are often assigned to time instants that allow quantitative evaluation of maps, mainly during QRS complex representing ventricular depolarization. Therefore, it is important to know the start as well as the end of the QRS complex as exact as possible.

This evaluation is relatively simple when using single leads. The start of a wave is assigned with the time instant where the trace deflects from the zero isoelectric line (zero voltage) or crosses it and the end of the wave with the time instant where the trace comes back to the zero isoelectric line or crosses it. During QRS complex, positive (negative) deflection is recorded when the depolarization wave moves toward (away from) the electrode. The highest point of the deflection is defined as its maximum (positive), the deepest point as its minimum 
(negative).

In maps, positive (negative) voltages occur on the chest in those areas where the depolarization wave moves toward them (away from them). The expressions "potential maximum" ("potential minimum") indicate the region of the map where the potential (voltage) is higher (lower) than that existing in all the neighbouring regions (Taccardi 1963). Therefore, a maximum (a minimum) does not need to be always positive (negative) in maps, mainly in the case of local extrema.

The beginning of the QRS complex in a sequence of isopotential maps is often ascribed to an increasing anterior maximum followed by an increasing minimum. This evaluation is usually based solely on visual inspection. More quantitative access is involved when using different methods of establishing the QRS onset (and offset). For example, using only a single selected lead as in standard electrocardiograms (usually $\mathrm{V}_{5}$ ), using the time of the first appearance in any of the individual leads, vector magnitude from Frank vectorcardiogram recorded simultaneously with body surface maps, or magnitude function or root mean square signal that include simultaneously all the recorded leads (Kozlíková 1990).

The first and the most important step in electrocardiographic interpretation is to distinguish between normal and abnormal findings (Shenasa 2018). Therefore, we need to know the physiological variability of isopotential maps. This was established mainly in adults (Green et al. 1985, Stilli et al. 1988). Much fewer papers dealt with children or adolescents and they mainly described isopotential maps of individual subjects (Liebman et al. 1981, Spach et al. 1966) rather than mean group maps (Green et al. 1985). The published map evaluation is mainly qualitative - based on visual inspection of maps. When analysing isopotential maps of QRS complex displaying the ventricular depolarization in children, the step (increment) between subsequent isopotential lines is usually $0.1 \mathrm{mV}$ or greater to ensure both a reasonable resolution of voltage values throughout the whole QRS complex as well as easy comparison of maps within one sequence (Kozlíková 1990, Green et al. 1985, Liebman et al., 1981, Kozlíková and Trnka 2014).

The aim of this study was to analyze how the pattern of the isopotential maps of the initial parts of the QRS complex may change when applying different step between the isopotential lines mainly from the point of view of maxima and minima behavior in groups of healthy young population of different age.

\section{Methods}

We studied 110 children and young adults from 9 years to 24 years old, 50 females (F) and 60 males (M) divided into 8 groups according to age and sex (Table 1). Each group consisted of 15 subjects except for one ( 5 females, group F4). None of the subjects had signs of cardiovascular diseases or cardiovascular risk. All subjects had normal 12-lead standard electrocardiographic and echocardiographic findings as well as blood pressure values.

Table 1. Main characteristics of studied subjects according to analyzed groups

\begin{tabular}{lcccccccc}
\hline Group & F1 & F2 & F3 & F4 & M1 & M2 & M3 & M4 \\
\hline $\begin{array}{l}\text { Sample size n } \\
\text { Age [y] }\end{array}$ & 15 & 15 & 15 & 5 & 15 & 15 & 15 & 15 \\
QRS duration [ms] & $9.8 \pm 0.1$ & $13.4 \pm 0.1$ & $18.3 \pm 0.1$ & $22.3 \pm 1.0$ & $9.8 \pm 0.1$ & $13.5 \pm 0.1$ & $18.3 \pm 0.1$ & $21.2 \pm 0.2$ \\
$\begin{array}{l}\text { The highest maximum } \\
\text { during the whole QRS }\end{array}$ & $2.5 \pm 0.6$ & $1.7 \pm 0.5$ & $1.2 \pm 0.3$ & $1.5 \pm 0.4$ & $2.4 \pm 0.5$ & $2.3 \pm 0.4$ & $2.3 \pm 0.5$ & $2.1 \pm 0.4$ \\
$\begin{array}{l}\text { [mV] } \\
\begin{array}{l}\text { The deepest minimum } \\
\text { during the whole QRS }\end{array}\end{array}$ & $-2.3 \pm 0.7$ & $-1.9 \pm 0.5$ & $-1.8 \pm 0.5$ & $-1.7 \pm 0.7$ & $-2.6 \pm 0.5$ & $-2.2 \pm 0.5$ & $-2.5 \pm 0.6$ & $-2.2 \pm 0.4$ \\
$\begin{array}{l}\text { [mV] } \\
\text { Maximal peak-to-peak }\end{array}$ & $4.4 \pm 1.2$ & $3.3 \pm 0.9$ & $2.9 \pm 0.8$ & $2.9 \pm 1.0$ & $4.4 \pm 1.1$ & $3.8 \pm 0.8$ & $4.6 \pm 0.6$ & $3.9 \pm 0.8$ \\
value during the whole & & & & & & & & \\
QRS [mV] & & & & & & & & \\
\hline
\end{tabular}

Values are given as mean \pm standard deviation. 


\section{A: Potential increment $0.10 \mathrm{mV}$}

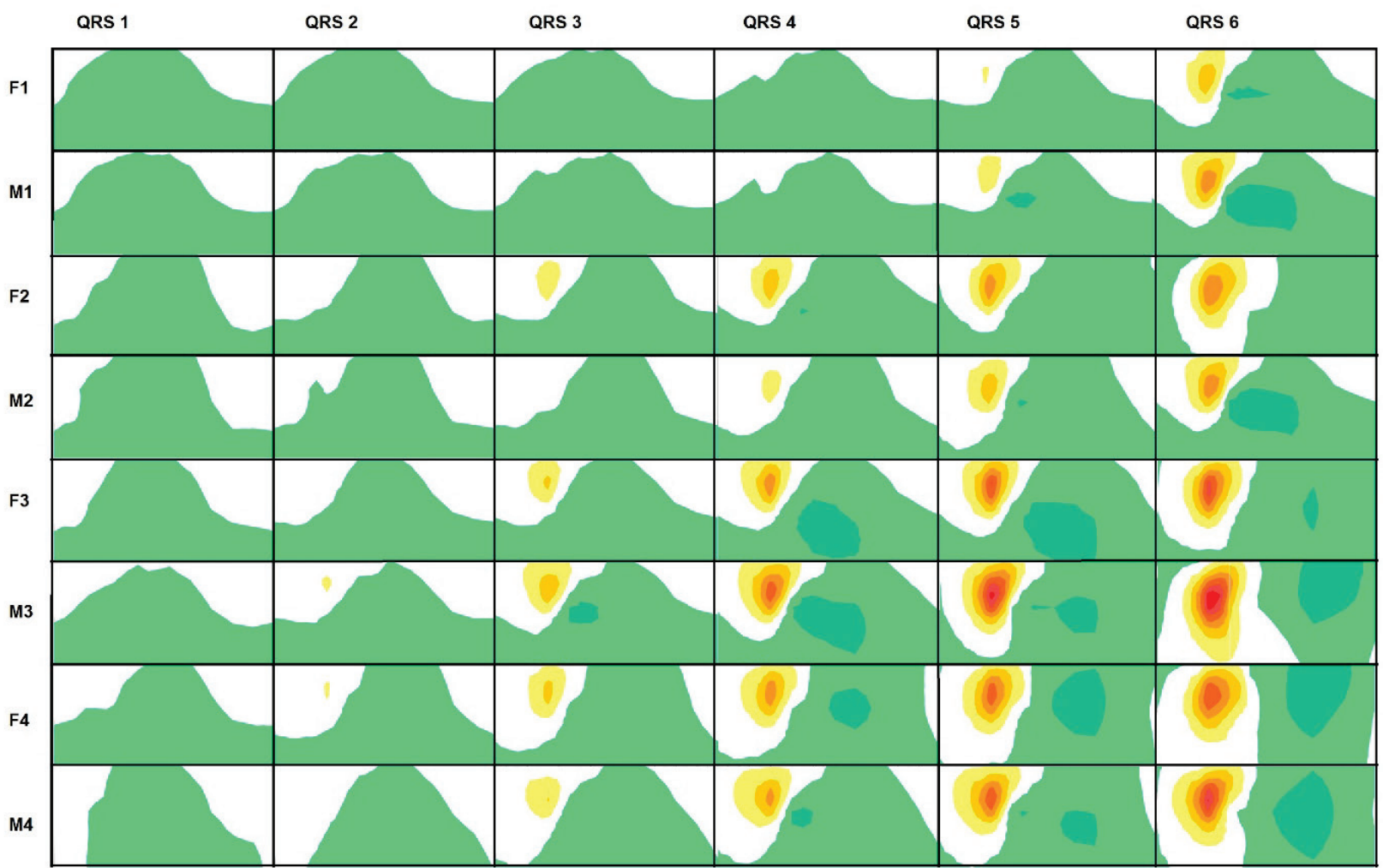

\section{B: Potential increment $0.02 \mathrm{mV}$}



Fig. 1. Group mean isopotential maps of the initial parts of the QRS complex displayed with different increment between isopotential lines is $0.1 \mathrm{mV}(\mathrm{A}, \mathrm{top})$ and $0.02 \mathrm{mV}$ (B, bottom). Each rectangle represents the chest surface from the clavicle to the waist with the left half corresponding to the front and the right half to the back. Yellow and red colors represent positive voltages, green and blue colors negative voltages. Zero line is between white and green area. 

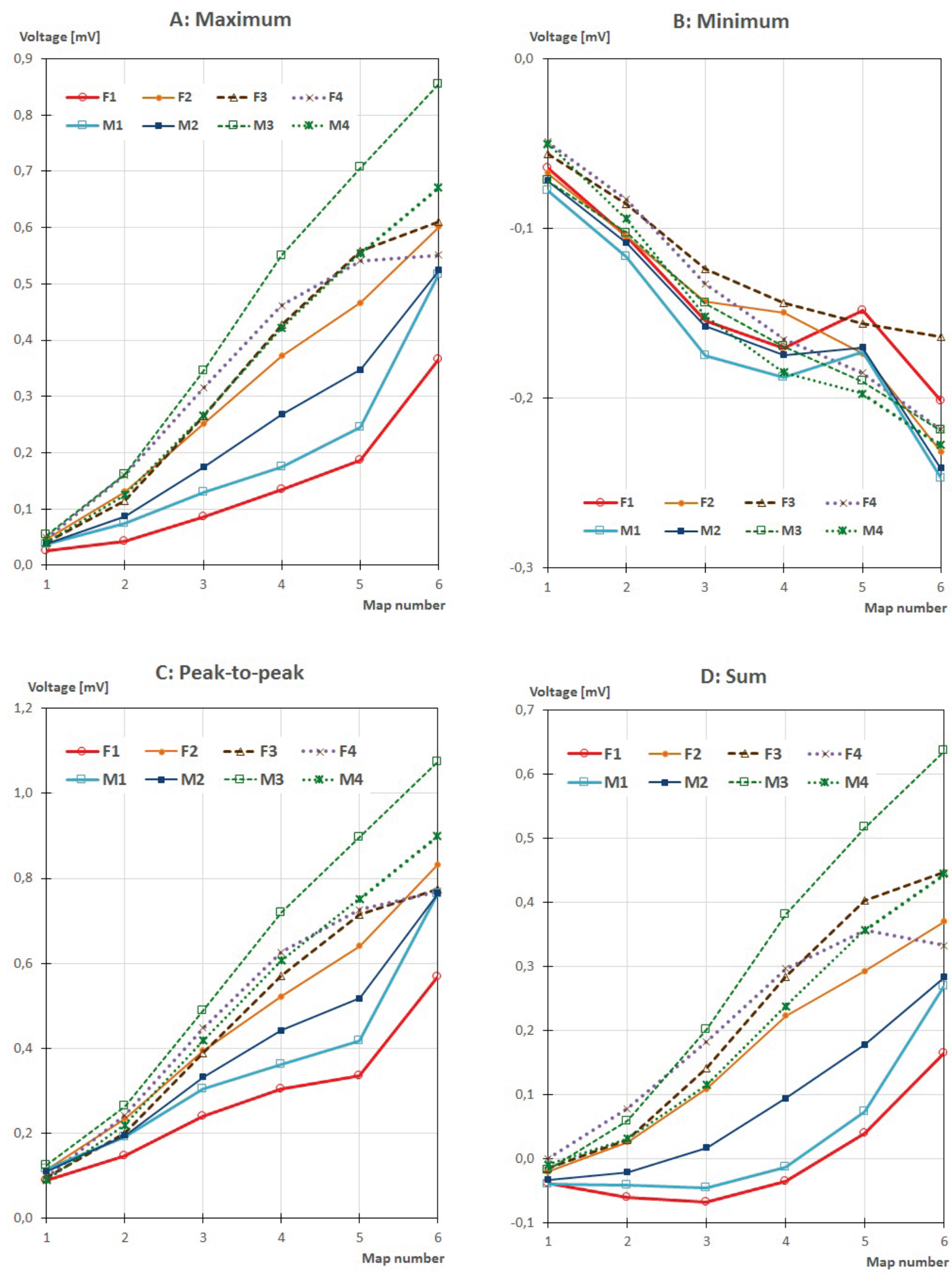

Fig. 2. Time courses of group mean extrema during the initial parts of ventricular depolarization (A: maxima, B: minima, C: peak-to peak values (maximum minus minimum), D: sum of extrema (maximum plus minimum)). 
Unipolar electrocardiograms for body surface potential mapping were registered using the limited 24-lead system after Barr based on a grid of 10 rows and 15 columns (Barr et al. 1971) implemented in the mapping system ProCardio (Rosík et al. 1997). All data were registered in supine position during normal expiration at sampling rate $500 \mathrm{~Hz}$ and filtered using Pipberger filter. Linear baselines (zero isoelectric lines) were taken through TP segments in each electrocardiogram. The onset and offset of the QRS complex were established manually from the root mean square (RMS) signal as those time instants when the signal was approaching the baseline (around $0.01 \mathrm{mV}-$ $0.02 \mathrm{mV}$ in the RMS signal) and stopped to decrease for at least three milliseconds when reading the values from the middle of the QRS complex.

For time normalization, the QRS complex duration of each subject was divided into 20 equidistant parts. We constructed 21 isopotential maps for each QRS complex (Kozlíková 1990), the first map corresponded to the QRS complex beginning, the last map to its end. Mean isopotential maps were constructed in every group and displayed using two different steps (increments) between isopotential lines: $0.10 \mathrm{mV}$ and $0.02 \mathrm{mV}$. The first six normalized time instants of the QRS complex (from QRS1 to QRS6) corresponding to about the first $25 \mathrm{~ms}$ were analyzed in this paper.

\section{Results}

The mean QRS duration in all subjects was $(93 \pm 12) \mathrm{ms}$ (range $71 \mathrm{~ms}$ to $123 \mathrm{~ms}$ ) that yielded to an approximate mean time interval between subsequent isopotential maps of $(5 \pm 1) \mathrm{ms}$ (Table 1$)$. There were no statistically significant differences in the QRS duration neither among all studied groups nor between males and females of the same age (according to ANOVA and Student t-test, respectively) (Kozlíková and Martinka 2009).

At the beginning of the QRS complex, all group mean isopotential maps revealed positive voltages in the upper part of the chest, mainly on the right side. The lower part of the chest was negative and this negativity reached the left shoulder in all groups (Fig. 1).

When evaluating the maxima and minima in the group mean QRS isopotential maps using the step $0.1 \mathrm{mV}$ between isopotential lines (Fig. 1A), we could recognize the first appearance of the maximum from the second map (QRS 2, groups M3 and F4) up to the fifth map
(QRS 5, groups F1 and M1). The first minimum appeared usually one or two maps later and reached lower values than the displayed maximum (according to visual inspection).

When using the smaller increment $0.02 \mathrm{mV}$ (Fig. 1B), the minimum was clearly seen in all first group mean maps (QRS 1), and the maximum appeared later only in three groups (M2 and M4 in QRS 2, F1 in QRS $3)$. At the very beginning, it moved only slightly downwards and then remained in the same position over the sternum during the evaluated time instants while increasing in magnitude. The minimum appeared always on the left anterior chest close to the maximum but somewhat lower. While becoming deeper, it moved to the left and then towards the back mainly in the older groups. When using the step of $0.1 \mathrm{mV}$, this movement of minimum was found only the oldest groups F3, F4, M3, and M4.

The changes of group extrema values are visible in Fig. 2. Mean maxima of all groups started at very low values (from $0.03 \mathrm{mV}$ to $0.05 \mathrm{mV}$ ) and increased continuously during the first observed six time instants (up to QRS 6, Fig. 2A). Mean minima of all groups started at very low values as well (from $-0.08 \mathrm{mV}$ to $-0.03 \mathrm{mV}$ ) and all decreased continuously up to the fourth observed time instant (up to QRS 4, Fig. 2B). In the fifth time instant, the minima of the youngest groups slightly increased (became less negative, F1, M1, and M2), but then continued to decrease. Peak-to-peak values (maximum minus minimum) behaved similar to maxima (Fig. 2C). Probably the most important information is in the sum of maximum and minimum, which reveals that the minima dominate in all evaluated groups in the first time instant (Fig. 2D). The sum becomes even more negative during next three maps in the youngest groups F1 and M1 while in the older groups it is positive starting from the second map (QRS 2).

\section{Discussion}

In this study, we were interested in changes of isopotential map patterns during the beginning of ventricular depolarization in children and young adults. Therefore, in discussion we compare our results only with papers dealing with similar topics and really published images of isopotential maps from the beginning of the QRS complex.

Taccardi (1963) recorded data from 15 healthy male human subjects aged 15 to 43 years in one of the 
very first papers dealing with body surface potential mapping. Electrocardiograms were recorded from 200 to 400 electrodes. A representative set of isopotential maps is displayed, but the age of the subject is not known (according to the projected stature probably an adult man). Nevertheless, the increment of isopotential lines is not linear (the smallest increment is $0.1 \mathrm{mV}$ ) and the first map displayed is approximately in the first third of the QRS complex showing an anterior maximum and a flatter dorsal minimum. According to the text, in early stages of ventricular depolarization, the maximum is generally located near the mid-sternal or left para-sternal line, at the level of the third to fifth intercostal space. The dorsal minimum is generally located near the posterior midline, at the same level, in rare cases, it can be observed in the vicinity of the left posterior axillary line or even more anteriorly. This pattern corresponds to our fifth or sixth normalized time instant (QRS 5 or QRS 6). Next published isopotential maps are similar to our findings. There is neither any information about QRS duration not any quantitative description of QRS extrema concerning our interests. No mean maps are available.

Spach et al. (1966) recorded body surface isopotential maps using 150 to 250 electrodes in 20 normal children aged 4 to 14 years. Maps of an 8-yearold girl are displayed representing typical patterns with the smallest increment between isopotential lines $0.1 \mathrm{mV}$. The QRS complex starts with a relatively small maximum over the sternum anteriorly, with a minimum at the left anterior axillary line or in the mid-axilla. This pattern corresponds to our fourth normalized time instant (QRS 4).

Young et al. (1974) presented normal thoracic surface potentials of 25 male subjects aged 16 to 64 years. Electrocardiograms were recorded from 126 electrodes. The displayed sequence of isopotential maps of ventricular depolarization of a normal male uses $0.25 \mathrm{mV}$ potential step. It is not possible to identify neither a maximum nor a minimum in the earliest stages $(0 \mathrm{~ms}, 10 \mathrm{~ms})$. The group mean duration of QRS complex was $76.6 \mathrm{~ms}$, the group peak extrema were $(1.8 \pm 0.5) \mathrm{mV}$ and $(-1.7 \pm 0.6) \mathrm{mV}$, flatter than our data as expected because of higher age of subjects.

Miller et al. (1980) recorded QRS isopotential maps 20 normal young adults, 20 to 35 years old with the same lead system as used in our study (24 electrodes). Zero linear baseline in each electrocardiogram was taken during UP (TP) segments or PR segments. Maps of a 25 -year-old woman are displayed with logarithmic scale of isopotential lines, the smallest step is $0.04 \mathrm{mV}$. The first map was displayed $10 \mathrm{~ms}$ after QRS onset. It revealed a dominating anterior maximum with much flatter dorsal inferior minimum. This pattern resembled our QRS 5 map of group F4.

Mean group isopotential maps of the QRS complex were computed for different ages in the paper of Green et al. (1985). The mean map of 47 males and 60 females aged 10 to 19 years $\left(2^{\text {nd }}\right.$ decade $)$ displays the early QRS complex with a maximum on the left anterior chest being about $0.4 \mathrm{mV}$ (according to drawn isopotential lines $0.1 \mathrm{mV}$ apart from each other). No minimum is seen in this map, only a negativity on the back and around the right shoulder. Similar pattern occurs in the mean map of 183 males and 164 females aged 20 to 29 years $\left(3^{\text {rd }}\right.$ decade) but with a flatter maximum (about $0.3 \mathrm{mV}$ ). Therefore, we assume that this map could be constructed about $20 \mathrm{~ms}$ after the QRS onset (in our case QRS 5), but there is no mention how was the QRS onset established. There is no information about QRS duration. Peak maxima and minima are flatter than in our study (Table 1), for example in the $2^{\text {nd }}$ decade males $(2.0 \pm 0.7) \mathrm{mV}$ and $(-2.2 \pm 0.7) \mathrm{mV}$, in females $(1.4 \pm 0.5) \mathrm{mV}$ and $(-1.7 \pm 0.6) \mathrm{mV}$.

More detailed analysis in $2 \mathrm{~ms}$ intervals is available in the work of Liebman et al. (1987) but only for individual subjects although 45 children aged 8 to

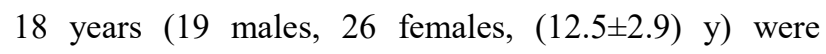
registered with a 180 electrode system. All map voltage values were rounded to be displayed with at most 32 levels for the total range of voltages (5-bit resolution). Probably this was the reason that only one color was used for the interval around the zero line $(-0.090 \mathrm{mV}, 0.090$ $\mathrm{mV}$ ) without distinguishing smaller positive or smaller negative voltages. As displayed in the published figures of isopotential maps of a 13-years old girl and a 13-years old boy, the locations of their maximum and minimum were similar to our maps but seen only when reaching about $0.1 \mathrm{mV}$. The QRS onset was established from the magnitude function. The mean QRS duration was (76.7 \pm 5.5$) \mathrm{ms}$, much shorter than in our groups. Group mean peak maximum was $(2.6 \pm 0.8) \mathrm{mV}$ and group mean peak minimum was $(-2.3 \pm 0.7) \mathrm{mV}$. Liebman et al. (1981) published similar results in 40 normal children, aged 8 to 18 years. In this paper, isopotential maps of the initial part of the QRS complex are displayed in a 9-year old boy. The maps are similar to those published later. The group mean QRS duration was (75.0 77.1) ms.

Kinoshita et al. (1984) published isopotential 
maps of 52 normal children aged 4 to 14 years (mean age $8.1 \mathrm{y}, 38$ males, 14 females) and 47 normal adults aged 21 to 47 years (mean age $24.4 \mathrm{y}, 31$ males, 16 females). Unipolar electrocardiograms were recorded from 87 points. The QRS onset was defined as the first of 5 successive increases in the root mean square signal what is in principle the same method as used in our study. Maps were displayed with $0.2 \mathrm{mV}$ step between isopotential lines. Examples of maps $6 \mathrm{~ms}$ after the QRS are given of an 8-year old boy and a 29-year adult male. In both cases, there is an anterior maximum and a flatter dorsal minimum, in the boy both extrema are located more inferiorly. Mean maps of children and adults are displayed at $10 \mathrm{~ms}$ after QSR onset with similar patterns - dorsal minimum and anterior maximum flatter in the adults than in the children. The pattern resembles our maps QRS 5 to QRS 6.

Asano et al. (2004) recorded body surface maps in a control group of 31 children aged from 2 to 13 years. Isopotential maps of a normal child are displayed, but neither the age nor the gender is known. The first time instant displayed was $15 \mathrm{~ms}$ after the QRS complex onset, again showing an anterior maximum and a flatter dorsal minimum comparable to that described by Taccardi (1963). The step between the isopotential lines is neither given nor readable from the figure. There is no mention, how was the QRS onset established.

In the paper Kozlíková (1990), only an example of QRS isopotential maps of a 19-years old young man is displayed with the increment of isopotential lines $0.5 \mathrm{mV}$, which does not allow to read the slight changes in voltages. Similar situation is in the paper Kozlíková and Trnka (2014), where more examples are given, but with the increment of isopotential lines $0.2 \mathrm{mV}$. These maps show the typical course of potential distribution during the whole QRS complex in good agreement with data obtained from different lead systems.

The authors are aware that more of the listed papers are of older data but they have not found newer ones dealing with isopotential maps of the very beginning of ventricular depolarization in children and young adults. Most of the listed papers describe the first maps only $15 \mathrm{~ms}$ to $20 \mathrm{~ms}$ after the QRS onset. The smallest used step is $0.1 \mathrm{mV}$ or higher except for Miller et al. (1980). The combination of these two facts could be the reason that the behavior of initial minimum in the 10 years old children remained hidden - masked by the larger potential step. No such calculations as presented in Fig. 2D were found in any published paper.
Another reason could be the description of maps given by Taccardi (1963), who is regarded as the "father of body surface potential mapping", namely that the anterior maximum represents the onset of ventricular depolarization. This could be also the explanation of shorter published group mean QRS durations as in our study (Table 1). However, our data correspond better with newer published QRS durations as established from standard electrocardiograms for different age groups children, adolescents, and young adults by Rijnbeck et al. (2014) and Kamphuis et al. (2018), varying from $71 \mathrm{~ms}$ to $126 \mathrm{~ms}$ ( $2^{\text {nd }}$ to $98^{\text {th }}$ percentile $)$.

The digital computer model of Selvester et al. (1968) can also support the initial anterior maximum. Twenty current dipoles, each representing a segment of the heart, were to project the activation sequence. The direction of each dipole was assigned normal to the average wave front of depolarization as it passed through that segment. An increasing anterior maximum corresponded to the initial activation of the septum in agreement with heart depolarization as described by Durrer et al. (1970). However, besides the central area on the left surface of the interventricular septum, the activation may start also in an area high on the anterior paraseptal wall or in a posterior paraseptal area. Moreover, exactly this area could cause the anterior minimum seen in our maps (Fig. 1B) because the wave front spreads opposite to the septal activation. The slow minimum growth could be explained by larger distance between the recording electrode on the anterior chest and the wave front. The measured voltage is namely directly proportional to the dimensions of the wave front (its cross-section as seen from the solid angle with the vertex in the electrode) and is inversely proportional to the squared distance of the electrode from the wave front (Kozlíková et al. 1994).

Our findings revealed some new facts concerning the behavior of maximum and minimum in the initial parts of the QRS complex as displayed in mean isopotential maps:

- When using the smaller increment between isopotential lines $(0.02 \mathrm{mV})$ continually increasing maximum and minimum can be seen in the very initial parts of the QRS complex, not only about $20 \mathrm{~ms}$ after its onset (as established from the root mean signal).

- The extrema representing the initial ventricular depolarization start at very low amplitudes of voltages, less than $0.1 \mathrm{mV}$. 
- In the youngest subjects, at first an anterior minimum appears followed later by an anterior maximum. The minimum dominates over the maximum during approximately $15 \mathrm{~ms}$. This pattern may represent the initial activation of the posterior paraseptal area rather than of the central area on the left surface of the interventricular septum that is usually considered as the onset of ventricular depolarization.

From the above follows that the often-applied criterion for the QRS onset - the increasing maximum on the anterior chest - should be reconsidered at least when it concerns the isopotential maps of children. Our findings may be also applied in determination of accessory pathways in patients with Wolff-ParkinsonWhite syndrome where the initial parts of the QRS complex (delta wave) are of interest (Tseng et al. 1998). The detection of the pre-excitation site is based mainly on the location of the minimum and its magnitude, which is also compared to the location and magnitude of the corresponding maximum. An abnormal early reversal pattern of ventricular depolarization (the absolute value of the potential minimum is greater than that of the potential maximum) can be used to distinguish between the location of the accessory pathway in the right or in the left ventricle. Non-invasive maps could also distinguish between epicardial and endocardial locations of accessory pathways, an important fact for catheter ablation (Ghosh et al. 2008).

\section{Conflict of Interest}

There is no conflict of interest.

\section{Acknowledgements}

This study was partially supported by the project VEGA $1 / 0807 / 18$ provided by the Ministry of Education, Science, Research and Sport of the Slovak Republic.

\section{References}

ASANO Y, IZUMIDA N, KAWANO S, SAWANOBORI T, HIRAOKA M: Resolution of abnormal body surface maps in children with atrial septal defect after intracardiac repair. J Cardiovasc Electrophysiol 15: 887-894, 2004.

BARR RC, SPACH MS, HERMAN-GIDDENS GS: Selection of the number and positions of measuring locations for electrocardiography. IEEE Trans Biomed Eng 18: 125-138, 1971.

DURRER D, VAN DAM RT, FREUD GE, JANSE MJ, MEIJLER FL, ARZBAECHER RC: Total excitation of the isolated human heart. Circulation 41: 899-912, 1970.

GHOSH S, AVARI JN, RHEE EK, WOODARD PK, RUDY Y: Noninvasive electrocardiographic imaging (ECGI) of a univentricular heart with Wolff-Parkinson-White syndrome. Heart Rhythm 5: 605-608, 2008.

GREEN LS, LUX RL, HAWS CW, WILLIAMS RR, HUNT SC, BURGESS MJ: Effects of age, sex, and body habitus on QRS and ST-T potential maps of 1100 normal subjects. Circulation 71: 244-253, 1985.

KAMPHUIS VP, BLOM NA, VAN ZWET EW, MAN S, TEN HARKEL ADJ, MAAN AC, SWENNE CA: Normal values of the ventricular gradient and QRS-T angle, derived from the pediatric electrocardiogram. J Electrocardiol 51: 490-495, 2018.

KINOSHITA A, OHTA T, HIRAI M, KUNO K, TOYAMA J, YAMADA K: Body surface isopotential maps of normal Japanese children. Jpn Circ J 48: 484-491, 1984.

KOZLÍKOVÁ K: Surface integral maps, their characteristics and methods of quantitative analysis. Bratisl Lek Listy 91 : $815-823,1990$.

KOZLÍKOVÁ K, HULÍN I, KNEPPO P, TYŠLER M, MURÍN J, BULAS J, BAKOŠOVÁ M, SAPÁKOVÁ E: Môžu izochrónne mapy komorovej aktivácie merané na povrchu tela odhalit’ infarktové ložisko? (in Slovak) Lékař a technika 25: 51-56, 1994.

KOZLÍKOVÁ K, MARTINKA J: Základy spracovania biomedicinskych meraní II. (in Slovak) Asklepios, Bratislava, 2009.

KOZLÍKOVÁ K, TRNKA M: Analysis of the ventricular depolarization using autocorrelation maps in young adult men and women. In: Electrocardiology 2014. Veda, Bratislava, 2014, pp 229-232.

LIEBMAN J, THOMAS CW, RUDY Y, PLONSEY R: Electrocardiographic body surface potential maps of the QRS of normal children. J Electrocardiol 14: 249-260, 1981. 
LIEBMAN J, THOMAS CW, SALAMONE R, RUDY Y, PLONSEY R: Electrocardiographic body surface potential maps of the QRS and T of normal children - qualitative description and selected quantitations. In: Pediatric and Fundamental Electrocardiography. LIEBMAN J, PLONSEY R, RUDY Y: (eds) Martinus Nijhofff Publishing, Boston, 1987, pp 381-388.

MILLER WT $3^{\text {rd }}$, SPACH MS, WARREN RB: Total body surface potential mapping during exercise: QRS-T-wave changes in normal young adults. Circulation 62: 632-645, 1980.

RIJNBEEK PR, VAN HERPEN G, BOTS ML, MAN S, VERWEIJ N, HOFMAN A, HILLEGE H, NUMANS ME, SWENNE CA, WITTEMAN JC, KORS JA: Normal values of the electrocardiogram for ages 16-90 years. J Electrocardiol 47: 914-921, 2014.

ROSíK V, TYŠLER M, TURZOVÁ M: Portable device for ECG mapping. In: Measurement '97. SAS, Bratislava, 1997, pp 367-370.

SELVESTER RH, SOLOMON JC, GILLESPIE TL: Digital computer model of a total body electrocardiographic surface map. An adult male-torso simulation with lungs. Circulation 38: 684-690, 1968.

SHENASA M: Learning and teaching electrocardiography in the 21st century: A neglected art. $J$ Electrocardiol 51: 428-429, 2018.

SPACH MS, SILBERBERG WP, BOINEAU JP, BARR RC, LONG EC, GALLIE TM, GABOR JB, WALLACE AG: Body surface isopotential maps in normal children, ages 4 to 14 years. Am Heart J 72: 640-652, 1966.

STILLI D, MUSSO E, BARONE P, CIARLINI P, MACCHI E, REGOLIOSI G, DEI CAS L, MANCA C, VISIOLI O, BO M, TACCARDI B: Newer data on the configuration and variability ranges of body surface maps in a sample of normal subjects. $J$ Electrocardiol 20: 1-20, 1987.

TACCARDI B: Distribution of heart potentials on the thoracic surface of normal human subjects. Circ Res 12: 341-352, 1963.

TSENG YZ, HSU KL, CHIANG FT, LO HM, TSENG CD, LIN JL: The use of body surface potential map for identifying sites of accessory pathway in patients with Wolff-Parkinson-White syndrome. Jpn Heart $J$ 39: 445-455, 1998.

YOUNG BD, MACFARLANE PW, LAWRIE TD: Normal thoracic surface potentials. Cardiovasc Res 8: 187-193, 1974. 